\title{
Living in a 'fat swamp': exposure to multiple sources of accessible, cheap, energy-dense fast foods in a deprived community
}

\author{
Patrick Saunders $^{1 *}$, Annie Saunders ${ }^{2}$ and John Middleton ${ }^{3}$ \\ ${ }^{1}$ Visiting Professor of Public Health, Faculty of Health Sciences, University of Staffordshire, College Road, Stoke-on-Trent, \\ Staffordshire ST4 2DE, UK \\ ${ }^{2}$ Carolan 57 Limited, 444 Quinton Road West, Quinton, Birmingham B32 1QG, UK \\ ${ }^{3}$ Honorary Reader in Public Health, University of Birmingham, Edgbaston, Birmingham B15 2TT, UK
}

(Submitted 13 October 2014 - Final revision received 10 February 2015 - Accepted 9 March 2015 - First published online 17 April 2015)

\begin{abstract}
This study assesses the levels of fats, including trans-fatty acids, and salt in common takeaway fast foods in a deprived urban municipality in the West Midlands, England, and implications in the context of the spatial distribution of fast food takeaways. The results of the compositional analysis of over 250 take-out foods were compared with established and derived standards. About $70 \%$ of products exceeded the recommendation that a meal should contain less than $30 \%$ of a Guideline Daily Amount (GDA). More than half of them exceeded $50 \%$ GDA for at least one metric, including $81 \%$ of all analyses for SFA. And 17\% of samples exceeded the GDA for SFA, including each of two meals that contained about twice the GDA. Over $30 \%$ samples exceeded the children's GDA for total fat or SFA. $27 \%$ of salt analyses exceeded the GDA. People in Sandwell are exposed to large portion sizes and high levels of fats and salt in takeaway foods, with levels in some foods having increased since 2010. Given this population's limited options to break out of a highly compromising environment of living simultaneously in a 'swamp' of unhealthy, readily accessible and cheap takeaways, and a 'desert' of healthy options, an immediate and innovative package of interventions is required.
\end{abstract}

Key words: Obesity: Takeaways: Trans-fatty acids: Portion size: Inequity

Dietary related diseases are a major cause of morbidity and premature mortality in Sandwell, one of the most deprived populations in England ${ }^{(1)}$. An estimated $28.7 \%$ of the adult population is obese, significantly higher than both the average for England $(24.1 \%)$ and the level reported in local authorities of a similar economic structure $(24 \cdot 1 \%)^{(2)}$. About $40 \%$ of year 6 children were obese or overweight in $2012^{(3)}$. While early mortality rates from CVD ( $<75$ years) have declined markedly since 1995 , they remain significantly higher than the national ${ }^{(2)}$. Sandwell is in the bottom $10 \%$ of local authorities for deaths from heart disease, which are $50 \%$ higher than neighbouring Dudley ${ }^{(4)}$.

While there has been some recent debate about the health impact of SFA ${ }^{(5,6)}$ and the adverse consequences of replacing SFA with carbohydrates ${ }^{(5)}$, there is evidence that total fat and SFA in particular are implicated in obesity and CVD ${ }^{(7-9)}$

Excessive salt is an important factor in hypertension ${ }^{(10)}$, and there are recommendations nationally to reduce the salt content of food eaten outside the home to achieve a safe level of intake ${ }^{(10-12)}$. Small-scale sampling of takeaway foods in Sandwell in 2010 found high levels of total fat, SFA and salt ${ }^{(13)}$.
Obesity and overweight are increasingly being considered in terms of the wider environmental context of the places in which people live and work, as well as factors acting at the individual level such as attitudes, behaviours and beliefs. While there is an established literature on the lack of access in deprived communities to retail fresh fruits and vegetables (food deserts), there is growing concern over the association between the fast food landscape and obesity ${ }^{(14)}$. Sandwell has been actively considering the impact of communities living in 'fat swamps' (areas with large numbers of outlets selling readily accessible, cheap, energy-dense pre-prepared food) as well as food deserts. Nowhere in Sandwell is more than a very short walk from one or more hot food takeaways ${ }^{(14)}$, and there is a significant association between such close residential proximity and deprivation. The density of outlets increases with deprivation effectively doubling the probability of a proximate outlet, and also increasing the choice and diversity of fast foods available $^{(14)}$. In addition, there is some, albeit modest, evidence that increased density of takeaways is associated with increased consumption of takeaway foods and levels of obesity ${ }^{(15)}$.

Abbreviations: TFA, trans-fatty acids; MBC, Metropolitan Borough Council; GDA, Guideline Daily Amount; SACN, Scientific Advisory Committee on Nutrition.

* Corresponding author: Professor P. Saunders, email carolan57@icloud.com 
Sandwell is clearly close to some level of market saturation. This presents a public health challenge in terms of promoting healthy diets, and also introduces the prospect of businesses turning to cheaper and more hazardous ingredients, as operating margins shrink. In particular, there is concern about the health effects of the cheaper, more stable, low maintenance trans-fatty acids (TFA) in food manufacture ${ }^{(8,16-18)}$. There are calls for a ban on TFA particularly in schools ${ }^{(19)}$, advice implemented internationally ${ }^{(20,21)}$. While their use is being actively managed and reduced in large-scale manufacturers, little work has been conducted on the extent of use in small-scale hot food takeaways, potentially a major source of exposure in Sandwell.

During 2013-4 the then Sandwell Primary Care Trust commissioned the purchase of over 250 takeaway food items, and their analysis for total fat, saturated and unsaturated fats, TFA and salt. The present paper reports the results of those analyses, data interpretation and recommendations for intervention.

\section{Methods and procedures}

\section{Literature review}

A literature review was conducted on recommended standards and exposures for fats (including TFA) and salt, and the levels reported in takeaway food products. For details of the search strategies, inclusion and exclusion criteria and decisions, and data extraction tables, see online Supplementary material.

\section{Takeaway food sampling and analysis}

Sandwell Metropolitan Borough Council (MBC) provided details of all hot food takeaways in the borough, and a dedicated officer to purchase the samples. A sampling framework was agreed to by Sandwell MBC, Primary Care Trust and Worcestershire Scientific Services. Sampling targeted independent retailers to include at least one in each ward, products previously sampled in published surveys from Sandwell and other local authorities in England and Northern Ireland to enable comparisons, and foodstuffs considered by Sandwell MBC as vulnerable to substitution and representative of local demand (see Table 1).

\section{Standards}

There have been multiple methods used to develop nutrient recommendations and guidelines and these vary between, and sometimes, within countries ${ }^{(22)}$. In the UK, Guideline Daily Amount (GDA) for women, men and children have been established for energy and seven other main nutrients - protein, carbohydrate, sugars, fat, SFA, fibre and salt. Although currently being replaced by reference intakes, at the time of this research GDAs were widely used by the industry with evidence that they were familiar to, and approved by, consumers, and encouraged healthy choices $^{(23)}$. GDA for total fat, SFA and salt were used as an acceptable exposure limit. In the absence of a GDA for TFA, a limit was derived from the literature.
Table 1. Sampling framework

Samples taken from independent retailers including pizza, chips, lamb
jalfrezi, fried battered products including fish, sweet and sour chicken,
and saveloy
At least one sample purchased from every ward in the Borough
Samples stored and transported to the laboratory in line with
good practice
Samples analyzed for:
Weight
Total fat
Saturated fat
Mono and unsaturated fats
TFA
Na
Salt from Na
Speciation for fish and lamb jalfrezi samples

TFA, trans-fatty acids.

The 2007 review $^{(18)}$ of the Scientific Advisory Committee on Nutrition (SACN) considered the evidence regarding the health effects of TFA, and advised that average TFA intake should not exceed $2 \%$ of food energy, equivalent to approximately $4.8 \mathrm{~g} / \mathrm{d}$. SACN also considered that further reductions could impact on attempts to reduce dietary SFA and on the consumption of animal products ${ }^{(18)}$. However, while only an estimated $3 \%$ of the general adult population consume more than $2 \%$ food energy as $\mathrm{TFA}^{(24)}$, that figure rises to $9 \%$ of males and $6 \%$ of females in the low income cohort ${ }^{(25)}$, which has implications for Sandwell's large deprived population. A meta-analysis study has suggested that a 1\% decrease in energy from TFA would deliver a $12.5 \%$ decrease in the risk of $\mathrm{CHD}^{(26)}$. Reducing food energy as TFA to below $1 \%$ for everyone in the UK requires an average decrease of $0.6 \%$, and it would reduce CHD risk by $5 \cdot 0-7 \cdot 5 \%^{(18)}$. Given these factors, an acceptable limit of $1 \%(2.4 \mathrm{~g} / \mathrm{d})$ was derived for this study, a level recommended by the American Heart Association $^{(27)}$. This review was unable to identify an appropriate limit for children.

\section{Results}

The literature searches identified 130 references. Reviews of titles and abstracts, examination of citation lists, references provided by experts, and exclusion of duplicates resulted in the inclusion of thirty-four papers which were retrieved and reviewed together with two local authority reports. Table 2 summarises levels of fat reported in takeaway foods (where reported in $\mathrm{g}$ ). Results were published for a range of takeaway products sampled in the UK, Ireland, the USA, and Australia. While there is some consistency in the products sampled, there is considerable variability in methods with different definitions of takeaway, metrics used, components tested, and populations assessed. This precludes meta-analysis but there are useful outcomes in terms of the impact of this sector on exposure and the relative position of Sandwell.

Only one paper recommending dietary standards for takeaways was identified, suggesting that a single meal should not exceed $30 \%$ of the GDA for any given component ${ }^{(28)}$. There is sparse data on the frequency takeaways are consumed. One US study reported young people using fast 
Table 2. Levels of fat $(\mathrm{g})$ in takeaway foods reported in the literature

\begin{tabular}{|c|c|c|c|c|}
\hline Product & Total fat $(\mathrm{g})$ & SFA (g) & TFA & Salt \\
\hline Fries & $19 \cdot 4 / 135^{(33)}$ & $3.8 / 135^{(33)}$ & $0.7 / 135^{(33)}$ & $0.8 / 100^{(35)}$ \\
\hline Pizza & $\begin{array}{l}7 \cdot 7 / 94^{(33)} \\
10-13 / 100^{(44)}\end{array}$ & $\begin{array}{l}4 / 94^{(33)} \\
\quad 4-5 / 100^{(44)} \\
9.6 \text { per slice, } \\
\text { weight not given } \\
(37)\end{array}$ & $\begin{array}{l}0.34 / 94^{(33)} \\
0.13 \text { per slice, } \\
\text { weight not given }^{(37)}\end{array}$ & $\begin{array}{l}1-2.4 / 100^{(35)} \\
9.5 \text { (per portion) }^{(45)}\end{array}$ \\
\hline \multirow{3}{*}{$\begin{array}{l}\text { Chicken tikka masala/ } \\
\text { pilau rice (meal) } \\
\text { Sweet/sour chicken/ } \\
\text { fried rice (meal) }\end{array}$} & $\begin{array}{l}60^{(32)} \\
61^{(13)}\end{array}$ & $23 \cdot 2^{(32)}$ & & $5 \cdot 5^{(32)}$ \\
\hline & $\begin{array}{l}61^{(13)} \\
70^{(32)}\end{array}$ & $\begin{array}{l}26 \cdot 4^{(13)} \\
20^{(32)}\end{array}$ & & $\begin{array}{l}6 \cdot 3^{(13)} \\
6^{(32)}\end{array}$ \\
\hline & $\begin{array}{l}55^{(13)} \\
13^{(32)}\end{array}$ & $\begin{array}{l}26 \cdot 4^{(13)} \\
24^{(46)}\end{array}$ & & $6 \cdot 3^{(13)}$ \\
\hline \multirow[t]{2}{*}{ Generic meals } & $\begin{array}{l}67^{(46)} \\
71 \text { (children) and }^{(47)} \\
76 \text { (adults) }^{(47)}\end{array}$ & $\begin{array}{l}6 \cdot 4^{(28)} \\
26 \text { (children) and } \\
26 \text { (adults) }(47)\end{array}$ & & $\begin{array}{l}4 \cdot 7-8 \cdot 07^{(45)} \\
5 \cdot 5^{(32)}\end{array}$ \\
\hline & $\begin{array}{l}\text { 81(adolescents, } \\
3 \text { meals in week) } \text { (48) }^{(48)} \text { (adolescents) } \\
430)\end{array}$ & $\begin{array}{l}28 \cdot 8 \text { (adolescents, } \\
3 \text { meals in week) } \\
15 \text { (adolescents) }^{(48)}\end{array}$ & & $2 \cdot 2 \mathrm{Na}^{(29)}$ \\
\hline
\end{tabular}

TFA, trans-fatty acids.

food outlets three to four times a week ${ }^{(29)}$; another found $30 \%$ of the sample consuming fast food on a typical day ${ }^{(30)}$. A UK study reported $10 \%$ of surveyed children using takeaways daily and over $50 \%$ twice or more a week ${ }^{(31)}$.

food samples were purchased and analysed including fortyseven portions of rice, thirty-six portions of fries, thirty-four fish, twenty-eight pizzas, twenty-five sweet and sour chicken, twenty-five battered products, twenty-three lamb jalfrezis, fourteen kebabs, and nine saveloys.

Table 3 shows the average weight of total fats, saturates, TFA, PUFA:SFA ratio and salt by food product. Levels of total fat, TFA and salt in pizzas bought in Sandwell are broadly similar to the international literature, although they are higher in saturated fat. However, there are some notable exceptions. Total fat in 'generic meals' (using pizza and chips as the example) in Sandwell was at the upper extreme of the range reported internationally, and saturated fat was more than double the internationally reported mid range.
Fries in Sandwell were lower in total fat and salt (although samples in Sandwell were not salted on purchase), and again higher in saturates. Both sweet and sour chicken and fried rice and chicken tikka masala and rice meals had higher levels of total and saturated fats and salt than those reported in both a 2010 Sandwell study ${ }^{(13)}$ and a recent English study ${ }^{(32)}$. It was found that $69 \%$ of the products had PUFA:SFA ratios less than 1 , and $30 \%$ less than $0 \cdot 1$.

Seventy-one of the 104 separate analyses exceeded the recommendation that a meal should contain less than $30 \%$ of any $\mathrm{GDA}^{(28)}$ for at least one measure (Table 4). Pizzas exceeded the recommendation for all measures. Of the thirty-three results below $30 \%$ GDA, seventeen were for TFA and five of the thirteen food groups contained no TFA. Fifty-four of the analyses exceeded 50\% GDA for at least one measure including twenty-one of twenty-six results for SFA. Eighteen results exceeded $100 \%$ of the GDA including 203\% GDA in pizza and chips for women/children (SFA), $173 \%$ GDA in sweet and

Table 3. Average weight of fat and salt content in takeaway portions

(values for example meals derived from individual components) (Mean values and standard deviations)

\begin{tabular}{|c|c|c|c|c|c|c|c|c|c|c|}
\hline \multirow[b]{3}{*}{ Product } & \multirow[b]{3}{*}{ No. of samples } & \multicolumn{8}{|c|}{ Weight (g/portion) } & \multirow[b]{3}{*}{ Fat PUFA:SFA ratio } \\
\hline & & \multicolumn{2}{|c|}{ Total fat } & \multicolumn{2}{|c|}{ Saturated fats } & \multicolumn{2}{|c|}{ Trans fats } & \multicolumn{2}{|c|}{ Salt } & \\
\hline & & Mean & SD & Mean & SD & Mean & SD & Mean & SD & \\
\hline Pizza & 28 & $43 \cdot 4$ & 11 & $20 \cdot 8$ & 5 & 0.3 & 1 & $5 \cdot 1$ & $1 \cdot 7$ & 0.3 \\
\hline Chips & 36 & 35.5 & 15 & $19 \cdot 8$ & 9 & 0.6 & 0.9 & 0.6 & 0.7 & 0.1 \\
\hline Fish & 36 & $24 \cdot 4$ & 8 & $14 \cdot 2$ & 5 & 0.5 & 0.6 & 0 & & 0.1 \\
\hline Other battered products & 25 & $36 \cdot 0$ & 13 & $19 \cdot 0$ & 8 & 0.6 & 0.7 & 1.9 & 1 & 0.2 \\
\hline Egg fried rice & 47 & $13 \cdot 9$ & 9 & $3 \cdot 0$ & 2 & 0 & & $2 \cdot 1$ & 1.8 & 1.9 \\
\hline Sweet sour chicken & 26 & $67 \cdot 0$ & 19 & $11 \cdot 0$ & $4 \cdot 2$ & 0 & & $4 \cdot 8$ & 2 & 2.5 \\
\hline Saveloy & 9 & $15 \cdot 2$ & 5 & $5 \cdot 3$ & 1.7 & 0 & & $1 \cdot 6$ & 0.8 & 0.5 \\
\hline Lamb jalfrezi & 24 & $44 \cdot 8$ & 10 & $10 \cdot 6$ & $2 \cdot 6$ & 0 & & 3.8 & 1.7 & $1 \cdot 7$ \\
\hline Donner kebab & 14 & $52 \cdot 4$ & 16 & $25 \cdot 7$ & 10 & 0.6 & $1 \cdot 7$ & $4 \cdot 3$ & 1.5 & 0.1 \\
\hline Pizza/chips & & 78.9 & & $40 \cdot 6$ & & 0.9 & & $5 \cdot 7$ & & 0.1 \\
\hline Sweet/sour chicken/rice & & 80.9 & & 30.9 & & 0 & & 6.9 & & $2 \cdot 2$ \\
\hline Fish/chips & & 59.9 & & $34 \cdot 0$ & & $1 \cdot 1$ & & 0.6 & & 0.1 \\
\hline Jalfrezi/chips & & $80 \cdot 3$ & & $30 \cdot 4$ & & 0.6 & & $4 \cdot 3$ & & 0.5 \\
\hline
\end{tabular}


Table 4. Proportion of recommended daily intake of fats and salt in takeaway samples

\begin{tabular}{|c|c|c|c|c|c|c|c|c|}
\hline \multirow[b]{2}{*}{ Product } & \multicolumn{2}{|c|}{$\%$ GDA total fat } & \multicolumn{2}{|c|}{$\%$ GDA saturated fat } & \multicolumn{2}{|c|}{$\begin{array}{l}\% \text { Acceptable daily } \\
\text { intake trans fats }\end{array}$} & \multicolumn{2}{|c|}{$\%$ GDA salt } \\
\hline & Male adults & $\begin{array}{c}\text { Female } \\
\text { adults/children }\end{array}$ & Male adults & $\begin{array}{c}\text { Female } \\
\text { adults/children }\end{array}$ & Male adults & $\begin{array}{l}\text { Female } \\
\text { adults }\end{array}$ & All adults & Children \\
\hline Pizza & 46 & 62 & 70 & 104 & 11 & 15 & 85 & 127 \\
\hline Chips & 38 & 51 & 66 & 99 & 26 & 36 & 10 & 15 \\
\hline Fish & 26 & 35 & 47 & 71 & 22 & 31 & 0 & 0 \\
\hline Other battered products & 38 & 52 & 63 & 95 & 25 & 35 & 32 & 48 \\
\hline Fried rice & 15 & 20 & 10 & 15 & 0 & 0 & 35 & 53 \\
\hline Sweet sour chicken & 71 & 96 & 37 & 56 & 0 & 0 & 80 & 120 \\
\hline Saveloy & 16 & 22 & 6 & 10 & 0 & 0 & 10 & 14 \\
\hline Lamb jalfrezi & 47 & 64 & 35 & 53 & 0 & 0 & 63 & 94 \\
\hline Donner kebab & 55 & 75 & 86 & 130 & 26 & 37 & 72 & 108 \\
\hline Pizza/chips & 84 & 113 & 136 & 203 & 37 & 51 & 95 & 142 \\
\hline Sweet/sour chicken/rice & 86 & 116 & 47 & 71 & 0 & 0 & 115 & 173 \\
\hline Fish/chips & 76 & 86 & 113 & 170 & 48 & 67 & 10 & 15 \\
\hline Jalfrezi/chips & 85 & 115 & 101 & 152 & 26 & 36 & 73 & 109 \\
\hline
\end{tabular}

GDA, Guideline Daily Amount.

sour chicken and fried rice for children (salt), and 170\% GDA in fish and chips for women/children (SFA). Fourteen of the thirty-nine results for children exceeded $100 \%$ of the GDA for at least one measure. For $69 \%$ of the samples, seven of the twenty-six salt analyses exceeded the GDA for salt.

A surprising finding was that portions of both pizzas and fries purchased in Sandwell were considerably larger than those reported elsewhere including the US, e.g. average Sandwell portion size for pizza of $365 \mathrm{~g}$ compared with $94 \mathrm{~g}^{(33)}$ and $102 \mathrm{~g}^{(34)}$, and for fries of $355 \mathrm{~g}$ compared with $120 \mathrm{~g}^{(33)}$.

\section{Discussion}

An adequate and nutritious diet is essential to a healthy, productive and fulfilling life. This is especially so for children whose physical, intellectual and emotional well-being is inextricably linked to what they eat, how much is consumed and, indeed, to what they can't afford to and so don't eat. Access to a healthy diet is a fundamental right and is predicated by a range of factors including personal knowledge and choice, convenience, availability, quality, cost, and social norms. The evidence is clear that deprivation compounds all these factors with poorer people buying more unhealthy foods with fewer healthy components while being exposed to circumstances that make such 'choices' inevitable ${ }^{(14)}$. The consequences of this unfortunate situation are manifest in Sandwell with its burden of obesity and CVD. Perversely, Sandwell has become simultaneously both a food desert and a fat swamp. Virtually the entire population of Sandwell lives a short walk from at least one takeaway. Consequently, the quality of these foods is of real significance for the health of the people of Sandwell. The present study has found high levels of exposure to fats including SFA and salt in takeaway foods. More than half the samples exceeded at least one GDA (or Acceptable Daily Intake) for fat, SFA or salt with a pizza-and-chips meal exceeding the recommended levels for all measures. The great majority of the foods provided more than $50 \%$ of a GDA in a single meal, and over $80 \%$ of that for SFA, which is of particular concern.
SFA are associated with factors that predispose people to CVD, although the evidence of a direct relationship is currently challenged $^{(6)}$. However, there is biological plausibility for an effect, and given the clear evidence that a balanced diet protects health, it is important that populations follow at least the current recommended intake of fats. The GDA is not a target for consumption, and so its use is a relatively conservative approach, and replacing SFA with PUFA will reduce risks. The PUFA:SFA ratios reported demonstrate that the present consumption of takeaway foods in Sandwell is incompatible with that substitution.

The levels of salt are of even more concern. Salt consumption has a profound effect on hypertension and the risk of CVD. A recent well- conducted systematic review highlighted the power of this relationship, and recommended a target reduction in salt intake to $3 \mathrm{~g} / \mathrm{d}$, the 2025 target level set by the National Institute for Health and Clinical Excellence for the $\mathrm{UK}^{(35)}$. GDA is currently 6 and $4 \mathrm{~g}$ for adults and children respectively ${ }^{(36)}$. Seven of the thirteen food groups sampled exceeded this target. This result becomes extreme, given that fries were not salted on purchase and were part of three of the four combination meals purchased for this study,

There were some remarkable results reported with single meals containing over 100\% GDA, including 203\% and $170 \%$ GDA of SFA, and $173 \%$ GDA of salt, given the evidence that young people routinely eat takeaway foods several times a week $^{(29-31)}$; that the fourteen of the thirty-nine results for children exceeded $100 \%$ of the GDA for at least one measure in a single visit is indeed a serious public health threat.

The results for TFA appear at first sight to be reassuring in that zero levels were reported in five food groups, and only nine of the twenty-six analyses exceeded 30\% GDA. But high levels of TFA were found in pizza-and-fish-and-chips meals, and TFA is a chemical to be scrupulously avoided. The overwhelming consensus in the literature is that TFA are linked with poor health outcomes, and their levels should indeed be reduced; several papers call for a ban on TFA, and the US Center for Disease Control has recommended the removal of TFA from school meals ${ }^{(19)}$; the advice should be successfully implemented in earnest by municipalities internationally ${ }^{(20,21)}$. 
While it is evident that the food industry has responded to these concerns by reducing the use of TFA, it is also clear from the analysis of foods in Sandwell that a real exposure hazard remains. The Sandwell results are especially important as they relate to the smaller independent outlets rather than the large chains which have been able to reduce TFA use without commercial disadvantage. It is also a sobering reality that the young and the deprived are more likely to use fast food takeaways, a disproportionately large community in Sandwell. Experience from New York has demonstrated the impact a municipal ban on TFA in major chains can have on levels of exposure $^{(37)}$. This is a limited option for Sandwell given that its market is dominated by small independent businesses as opposed to the major chains, the limited powers an English Council has to legislate in this area, and the potential access to takeaways in the four bordering Councils.

It is entirely legitimate for Councils to consider those powers they have (for e.g. planning and licensing) to enforce a TFA reduction, to lobby the Government on delegating powers to local authorities to respond to local public health issues, and collaborate with neighbouring councils on a regional approach to ensure that businesses in one area are not prejudiced by initiatives in another.

It is true that Sandwell, as several other UK Councils, has used its planning and licensing powers to restrict the siting of takeaways in the vicinity of schools. While this sends out a very powerful political statement, it is doubtful whether such restrictions will have an impact on obesity especially in an environment where there are so many other available takeaway options. Such readily accessible and cheap foods is inevitably attractive to deprived communities, given that food prices increased $12 \%$ in real terms between 2008 and 2012, while median incomes in the most deprived decile fell $12 \%$ between 2002 and $2011^{(38)}$. Analysis of the cost of 'more healthy' and 'less healthy' foods over a very similar period (2002-12) found that the former were consistently more expensive, and that this gap had widened with healthier foods being almost three times more expensive by $2012^{(39)}$. For poorer social groups avoiding the expense of cooking entirely is a cost effective way of sourcing energy. These are the same populations experiencing high levels of unemployment and limited opportunities to develop businesses. There are, clearly, strong political, social and economic reasons for not considering a blanket restriction on takeaways given the role such businesses play in entry-level employment and business opportunities for disadvantaged communities ${ }^{(40)}$. In addition to the composition of takeaways, another major concern for Sandwell is the apparent supersizing of portions in the independent sector, presumably in response to intense market competition. A surprising finding was that portions of both pizzas and fries purchased in Sandwell were considerably larger than those reported elsewhere including some American research ${ }^{(33)}$. Rather than trying to ban such foods, a more realistic and effective intervention is to challenge and change what's on offer, how much is on offer, and how it's been prepared. As Neckerman put it in a recent BMJ Editorial, 'change the menu not the venue ${ }^{(40)}$.

Trading Standards and Environmental Health, with responsibilities to enforce food standards and safety legislation including labelling and composition, have critical roles in ensuring that health and nutrition claims comply with current legislation, and promote government food policy across the industry. It is necessary for the government and the local authorities to encourage and enable businesses to use healthier ingredients and techniques. This 'non-regulatory' work is just as important as regulatory interventions, if not more so, given the potential for the major improvements over and above mere compliance with the law to make meaningful changes in the Sandwell community consumption pattern.

Previous work in Sandwell demonstrated the value of targeting food safety interventions on an area basis, rather than through a simple individual business risk assessment. This approach delivered statistically significantly improved food hygiene scores during its implementation from $2008-10^{(41)}$. There may be some value in adopting the same approach to improving the dietary quality of fast food takeaways in Sandwell and elsewhere.

In summary, people in Sandwell are exposed to large portion sizes and high levels of fats and salt in takeaway foods, with levels in some foods having increased further since 2010. They have limited options to break out of this highly compromising environment due to high levels of deprivation, limited transport options and the dubious distinction of living simultaneously in a 'swamp' of unhealthy, readily accessible and cheap takeaways, and a 'desert' of healthy options. A package of interventions is required including: the use of local planning and regulatory powers; undertaking environmental and educational interventions targeting consumers and businesses; addressing portion sizes $^{(42)}$; stimulating demand for healthier products; framing school food procurement policies; adapting the roles of Council enforcement officers to persuade the industry to promote healthy food preparation techniques; and launching a local social marketing campaign ${ }^{(43)}$.

\section{Strengths and limitations of study}

The present investigation effectively utilized the skills and resources of the key public health agencies and professional groups. It targeted the independent retail sector, the largest source of takeaway foods in Sandwell, subject to intense economic pressure and competition. Sampling covered each ward in the Borough.

Testing for fraudulent substitution of products revealed very little information and weakened the reliability of the limited sampling resource. The discretion of local enforcement officers in determining representative products was partially subjective, and led to a disproportionate sampling of some products at the expense of others (this is reflected in some of the large standard deviations reported in Table 3).

\section{Supplementary material}

To view supplementary material for this article, please visit http://dx.doi.org/10.1017/S0007114515001063 


\section{Acknowledgements}

This research received no specific grant from any funding agency, commercial or not-for-profit sectors.

Paul Hancock, Worcestershire Scientific Services, provided technical expertise on sampling methods and managed sample analysis.

Richard Norton, Sandwell MBC, provided data on location of takeaway food businesses and a dedicated staff member to purchase, store and transport food samples.

Contribution of authors were as follows: P. S. managed the programme of work including the development of sampling and analytical protocols, supervised the data analysis, interpreted results and led on early drafts of the paper; A. S. conducted the data analysis; J. M. secured funding from Sandwell Primary Care Trust and contributed to the design and management of the programme. All authors read and commented on drafts of the paper.

None of the authors has any conflicts of interest to declare.

\section{References}

1. Research Sandwell (2014) Sandwell Trends, Deprivation in Sandwell. http://www.sandwelltrends.info/ (accessed 9 February 2015).

2. SEPHO (2012) Cardiovascular disease health profile Sandwell. http://www.sepho.org.uk/NationalCVD/Archive/ 2012/docs/5PF_CVD\%20Profile.pdf (accessed 9 February 2015).

3. Health and Social Care Information Centre (2013) National Child Measurement Programme - England, 2012-13 school year [NS]. http://www.hscic.gov.uk/catalogue/ PUB13115 (accessed 9 February 2015).

4. Sandwell MBC (2012) Annual Report 2012: A Public Health Council, p. 8. http://sandwelltrends.info/themedpages/ Health/DPHReports (accessed 9 February 2015).

5. Lawrence GD (2013) Dietary fats and health: dietary recommendations in the context of scientific evidence. $A d v$ Nutr 4, 294-302.

6. Wise J (2014) Evidence does not support guidelines on saturated fat, researchers say. BMJ 348, g2238.

7. Salter AM (2013) Dietary fatty acids and cardiovascular disease. Animal 7, Suppl. 1, 163-171.

8. Willet WC (2012) Dietary fats and coronary heart disease. J Intern Med 272, 13-24.

9. Baum SJ, Kris-Etherton PM, Willett WC, et al. (2012) Fatty acids in cardiovascular health and disease: a comprehensive update. J Clin Lipid 6, 216-234.

10. Scientific Advisory Committee on Nutrition (2003) Salt and Health. London: HMSO.

11. He FJ, Li J \& Macgregor GA (2013) Effect of longer-term modest salt reduction on blood pressure. Cochrane Database Sys Rev 4, CD004937.

12. Taylor RS, Ashton KE, Moxham T, et al. (2011) Reduced dietary salt for the prevention of cardiovascular disease: a meta-analysis of randomized controlled trials. $A m J$ Hypertens 24, 843-853.

13. Sandwell MBC (2011) How Healthy are our Takeaways? Sandwell: Sandwell Regulatory Services.

14. Rudge G, Suglani N, Jenkinson D, et al. (2013) Are fast food outlets concentrated in more deprived areas? a geo-statistical analysis of an urban area in Central England. I Epidemiol Comm Health 67, Suppl. 1, A14.
15. Burgoine T, Forouhi NG, Griffin SJ, et al. (2014) Associations between exposure to takeaway food outlets, takeaway food consumption, and body weight in Cambridgeshire, UK: population based, cross sectional study. BMJ 348, g1464.

16. Laake I, Pedersen JI, Selmer R, et al. (2012) A prospective study of intake of trans-fatty acids from ruminant fat, partially hydrogenated vegetable oils, and marine oils and mortality from CVD. Br J Nutr 108, 743-754.

17. Hunter JE, Zhang J \& Kris-Etherton PM (2010) Cardiovascular disease risk of dietary stearic acid compared with trans, other saturated, and unsaturated fatty acids: a systematic review. Am J Clin Nutri 91, 46-63.

18. Scientific Advisory Committee on Nutrition (2007) Update on Trans Fatty Acids and Health. London: TSO.

19. CDC (2009) Nutrition Standards for Foods in Schools. http:// www.cdc.gov/healthyyouth/nutrition/pdf/nutrition_factsheet_ parents.pdf (accessed 9 February 2015).

20. Lichtenstein AH (2012) New York City trans fat ban: improving the default option when purchasing foods prepared outside of the home. Ann Intern Med 157, 144-145.

21. Ontario Ministry for Education (2014) Healthy Schools: Trans Fat Standards Regulation. http://www.edu.gov.on.ca/eng/ healthyschools/healthier.html (accessed 9 February 2015).

22. Aranceta J \& Perez-Rodrigo C (2012) Recommended dietary reference intakes, nutritional goals and dietary guidelines for fat and fatty acids: a systematic review. Br J Nutr 107, S8-S22.

23. Food and Drink Federation (2009) Seven Voices. GDA Labels Making a Real Difference. A Review of Their Impact. http:// www.fdf.org.uk/corporate_pubs/sevenvoices.pdf (accessed 9 February 2015).

24. Henderson L, Gregory J, Irving K, et al. (2003) The National Diet and Nutrition Survey: Adults Aged 19-64 years. London: HMSO.

25. Nelson M, Erens B, Bates B, et al. (2007) Low Income, Diet and Nutrition Survey. Volume 2 - Food Consumption, Nutritional Intake. London: TSO.

26. Oomen CM, Ocké MC, Feskens EJM, et al. (2001) Association between trans fatty acid intake and 10-year risk of coronary heart disease in the Zutphen Elderly Study: a prospective population-based study. Lancet 357, 746-751.

27. American Heart Association Nutrition Committee, Lichtenstein AH, Appel LJ, et al. (2006) Diet and lifestyle recommendations revision 2006: a scientific statement from the American Heart Association Nutrition Committee. Circulation 114, 82-96.

28. Wellard L, Glasson C \& Chapman K (2012) Fries or a fruit bag? investigating the nutritional composition of fast food children's meals. Appetite 58, 105-110.

29. Larson N, Neumark-Sztainer D, Laska MN, et al. (2011) Young adults and eating away from home: associations with dietary intake patterns and weight status differ by choice of restaurant. J Am Diet Ass 111, 1696-1703.

30. Bowman SA, Gortmaker SL \& Ebbeling CB (2004) Effects of fast-food consumption on energy intake and diet quality among children in a national household survey. Pediatrics 113, 112-118.

31. Patterson R, Risby A \& Chan M-Y (2012) Public health consumption of takeaway and fast food in a deprived inner London Borough: are they associated with childhood obesity? BMJ Open 2, e000402.

32. Local Government Group (2011) Survey of the Composition of Certain Takeaway Food. Local Authorities Food Standards Survey 14. London: Local Government Regulatory Support Group.

33. Tyburczy C, Mossoba MM \& Rader JI (2012) Profile of trans fatty acids (FAs) including trans polyunsaturated FAs in 
representative fast food samples. I Agr Food Chem 60, 4567-4577.

34. Dunford E, Webster J, Woodward M, et al. (2012) The variability of reported salt levels in fast foods across six countries: opportunities for salt reduction. Can Med Ass J 184, 1023-1028.

35. National Institute for Health and Clinical Excellence (NICE) (2010) Prevention of cardiovascular disease. http:// guidance.nice.org.uk/PH25 (accessed 9 February 2015).

36. Food and Drink Federation (2014) Guideline Daily Amounts. http://www.gdalabel.org.uk/gda/gda_values.aspx (accessed 9 February 2015).

37. Angell SY, Cobb LK, Curtis CJ, et al. (2012) Change in trans fatty acid content of fast-food purchases associated with New York City's restaurant regulation: a pre-post study. Ann Intern Med 157, 81-86.

38. Department of Environment, Food, and Rural Affairs (2012) Food statistics pocketbook 2012. https://www.gov.uk/government/statistics/food-statistics-pocketbook-2012 (accessed 9 February 2015)

39. Jones NRV, Conklin AI, Suhrcke M, et al. (2014) The growing price gap between more and less healthy foods: analysis of a novel longitudinal UK dataset. PLOS ONE 9, e109343.

40. Neckerman KM (2014) Takeaway food and health change the menu, not the venue. BMJ 348, g1817.

41. Sandwell MBC (2013) Environmental public health tracking. In Sandwell Report of First Year's Pilot. Sandwell Public Health Technical Report 2013. Sandwell: Sandwell MBC.
42. Vermeer WM, Steenhuis IHM \& Poelman MP (2014) Small, medium, large or supersize? the development and evaluation of interventions targeted at portion size. Int $J$ Obes 38, S13-S18.

43. Public Health England, Chartered Institute of Environmental Health and the Local Government Association (2014) Healthy People, Healthy Places Briefing. Obesity and the Environment: Regulating the Growth of Fast Food Outlets. London: PHE Publications.

44. Jaworowska A, Blackham T, Davies IG, et al. (2013) Nutritional challenges and health implications of takeaway and fast food. Nutr Rev 71, 310-318.

45. Jaworowska A, Blackham T \& Stevenson L (2012) Determination of salt content in hot takeaway meals in the United Kingdom. Appetite 59, 517-522.

46. Powell LM \& Nguyen BT (2013) Fast-food and full-service restaurant consumption among children and adolescents: effect on energy, beverage, and nutrient intake. JAMA Pediatr 167, 14-20.

47. Paeratakul S, Ferdinand DP \& Champagne CM (2003) Fastfood consumption among US adults and children: dietary and nutrient intake profile. J Am Diet Ass 103, $1332-1338$

48. French SA, Story M \& Neumark-Sztainer D (2001) Fast food restaurant use among adolescents: associations with nutrient intake, food choices and behavioural and psychosocial variables. Int J Obes 25, 1823-1833. 